\title{
Butter-weld Interface Microstructural Analysis Employing NCS and LAMS Sections
} Adiana Nascimento Silva ${ }^{*} \mathbb{D}$, Esdras Carvalho Costa ${ }^{b}$, Roneles de Santana Silva ${ }^{b}$, José Gonçalves de

\author{
Almeida , Severino Jackson Guedes de Lima ${ }^{\dagger}$, Tibério Andrade dos Passos ${ }^{d}$ \\ ${ }^{a}$ Universidade Federal Rural do Semi-Árido - UFERSA, Departamento de Engenharias, Caraúbas, \\ RN, Brasil \\ ${ }^{b}$ Universidade Federal da Paraíba - UFPB, Programa de Pós-graduação em Engenharia Mecânica, \\ João Pessoa, PB, Brasil \\ ${ }^{c}$ Universidade Federal da Paraíba, Centro de Tecnologia, Departamento de Engenharia de Mecânica, \\ João Pessoa, PB, Brasil \\ ${ }^{d}$ Universidade Federal da Paraíba - UFPB, Departamento de Engenharia de Materiais, João Pessoa, \\ $P B$, Brasil
}

Received: January 11, 2019; Revised: December 22, 2019; Accepted: January 12, 2020

The formation of brittle microstructures around the fusion line in dissimilar welds has required a deeper microstructural analysis in this region. The study becomes more relevant when these welds are used in environments that facilitate hydrogen embrittlement. The present work aims to characterize the microstructure and hardness at the diluted zone interface in joints welded with dissimilar materials. Aiming for a better efficacy in the microstructural characterization of this zone, samples of both normal cross-section (NCS) and section with slope were used, according to the low-angle microsectioning (LAMS) technique, which allows a greater amplification of partially mixed zones (PMZs). The results indicated the diffusion of carbon from the heat-affected zone (HAZ) towards the fusion line which, in combination with other alloying elements, form highly brittle carbides. In turn, the hardness of the base metal and the HAZ was reduced after post weld heat treatment, whereas in the weld metal an opposite behavior was observed. The dissimilar interface was promising for applications in environments facilitating hydrogen embrittlement, especially regarding the characteristics of zone $\Phi$.

Keywords: Dilution, macrosegregation, martensite, buttering.

\section{Introduction}

The application of dissimilar welded joints is present in the power generation, petrochemical and transformation industries $^{1-5}$. In the oil and gas extraction system, mainly offshore, these joints are subjected to very unfavorable working conditions, both in terms of oxidation and embrittlement and high pressures ${ }^{6-9}$. These conditions have demanded the adoption of materials and manufactoring processes that allow better mechanical properties and a lower sensitivity to the presence of hydrogen ${ }^{10,11}$. Among these materials Nibased superalloys stand out for their good performance in terms of mechanical and corrosion resistance ${ }^{12}$. Among the components of the offshore system that are constituted by dissimilar welding, there are components such as Manifolds, Flowlines and Risers ${ }^{10,13}$. These have used high-strength low-alloy (HSLA) steels, for example 8630 and F22, which receive buttering weld multipasses with Ni-based weld metal (e.g. alloy 625 and 725) ${ }^{14,15,2}$. In view of the need to meet the hardness criteria of $22 \mathrm{HRC}$ or $250 \mathrm{HV} 10$ specified by NACE MR0175 / ISO $151567^{16}$ for the heat-affected zone (HAZ), the welded material is subjected to a post weld heat treatment (PWHT).

The heat generated by passing the welding torch on the metal surface creates a complex microstructure in the $\mathrm{HAZ}$ that may contain mainly fresh martensite in the base metal ${ }^{17}$. The thermal cycle in arc welding consists of rapid

*e-mail: adianans@gmail.com

$\dagger$ in memorium heating (hundreds of degrees per second), followed by relatively rapid cooling (on the order of tens to hundreds of degrees per second $)^{2}$. The microstructural change in the HAZ is dependent on the heating and cooling rates which, in turn, are determined by the welding heat, the thickness of the workpiece to be welded, the geometry and interpass temperature ${ }^{18}$. Subsequent microstructural changes directly affect mechanical properties, especially in HAZ, which are directly interconnected to the hardness of the material ${ }^{2}$. Thus, a microstructural characterization process that allows for a more expanded microstructural survey is of fundamental importance. In this sense, the low-angle microsectioning LAMS technique stands out for its ability to enlarge partially diluted zones (PMZs), due to the sectioning of the samples with angle less than $90^{\circ}$, thus ensuring a much more precise microstructural characterization of these zones, thus allowing a characterization microstructural efficiency of these zones for the welding and PWHT conditions employed. This way, one can perform execution of punctual indentations that specifically cover each zone in isolation. Another important factor in adopting the LAMS technique is that dissimilar welding is considerably more complex than welding similar materials, being characterized by large composition gradients and microstructural changes around the melting line ${ }^{19}$.

Even given the hardness criteria specified above, a number of failures in dissimilar underwater welds have occurred. The cause is attributed to hydrogen embrittlement resulting from the cathodic protection process which, in 
turn, is directly associated with the microstructure of the material, especially the presence of the PMZs around the fusion line ${ }^{20}$. The most notable case was that of the Thunder Horse platform operated by BP in the Gulf of Mexico in $2006^{10}$. Among the materials cited in the literature, the joints between $8630 \mathrm{M} / 625$ are mentioned in the history of failures ${ }^{13}$. The F22 / 625 joint has shown promise due to the lower carbon content in its composition. The occurrence of hydrogen embrittlement, among other factors, is due to the microstructure at the dissimilar interface, mainly due to the precipitation of carbides ${ }^{21,22}$. The microstructure of the interface is a function of the chemical composition of the materials, the welding process and the PWHT. The latter has generated a metallurgical dilemma since, as the hardness of the HAZ is reduced by the PWHT, the carbon of the base metal diffuses towards the fusion line ${ }^{23}$. According to the PWHT parameters, the carbon can reach the planar growth zone $(\Phi)$, increasing its hardness, and consequently making it more susceptible to hydrogen embrittlement, due to the presence of $\mathrm{M}_{7} \mathrm{C}_{3}$ carbide ${ }^{24}$.

The motivation of the present study is the achievement of a microstructural analysis of the weld with base metal, forged steel ASTM A182 F22, buttered with Ni-base alloy, Inconel 625 . In this analysis, the techniques of normal cross-section (NCS) and low-angle microsectioning (LAMS) were used, the latter allowing an expansion of the dissimilar interface, thus guaranteeing more reliable punctual microhardness results for partially mixed zones (PMZs), such as example $\Phi$ and $\mathrm{M}$, which are usually quite narrow ${ }^{25,19}$. Considering the results obtained in the literature for the forged steel ASTM A182 F22, which aimed to reach an optimal point for $\mathrm{PWHT}^{24}$, a PWHT of 6 hours at $677^{\circ} \mathrm{C}$ was carried out in this work, in order to compare its effectiveness in relation to other conditions already studied. The results were very satisfactory both in terms of cost / time and in meeting the hardness requirements established in the NACE MR0175 16 standard for subsea applications.

\section{Experimental Procedure}

\subsection{Materials}

In the dissimilar buttering layer, forged ASTM A182 F22 steel was used as the base metal (BM) and as the weld metal (WM) the Ni-base alloy, Inconel 625 (ERNiCrMo-3). Table 1 shows the chemical composition of both materials.

\subsection{Welding process and PWHT}

In the buttering process, the Gas Metal Arc Welding (GMAW) method was used, where the main parameters are represented in Table 2. The protection of the arc and the region of the buttering was made by the gas mixture composed of gases $\mathrm{Ar}$ and $\mathrm{He}$, in the proportions of $75 \%$ and $25 \%$, respectively. In the buttering, a total of 16 weld beads were distributed in four layers and each layer was composed of four beads. This overlap of beads was sufficient to ensure that after the machining the addition metal was $9.5 \mathrm{~mm}$ thick enough to prevent ASTM A182 F22 steel from undergoing severe thermal input after the application of the joint.

After the buttering process the part was submitted to a PWHT for 6 hours at $677 \pm 10^{\circ} \mathrm{C}$. In the definition of these PWHT conditions, the feasibility of the process was prioritized from the practical point of view, as well as the condition that presented the parameter Hollomon-Jaffe (HJP) between the range of 19,500 and 20,000, since the authors Dai and Lippold ${ }^{25}$ verified, in this range, good results in reducing the HAZ hardness level of the ASTM A182 F22 steel. The parameter HJP is defined by Equation 1 and considers the temperature $(\mathrm{T})$ in Kelvin and time (t) in hours ${ }^{26}$. In the PWHT, a heating rate of $20^{\circ} \mathrm{C} / \mathrm{min}$ was used, and the material was cooled in the still air.

$$
H J P=T *(20+\log t)
$$

\subsection{Extraction and sample preparation for microstructural characterization}

Figure 1 (a) shows the procedure for the extraction of the samples by the process of wire cutting, while in the images (b) and (c) a comparison of the samples NCS and LAMS.

Bourgeois ${ }^{27}$ points out that LAMS can prolong the transition region by up to 10 times when compared to NCS. The cut allowed the extraction of samples with an angle of approximately $8^{\circ}$ which, according to the image of Figure 1 (a), comprises the fusion line and the surface in which the cut was performed (red line), resulting in an enlargement of approximately sevenfold. The samples had a square cross section of approximately $20 \mathrm{~mm}$ in side.

Table 1. Chemical composition (wt $\%$ )

\begin{tabular}{cccccccccccccccc}
\hline & $\mathbf{C}$ & $\mathbf{N i}$ & $\mathbf{C r}$ & $\mathbf{M o}$ & $\mathbf{M n}$ & $\mathbf{A l}$ & $\mathbf{N b}$ & $\mathbf{S i}$ & $\mathbf{C u}$ & $\mathbf{P}$ & $\mathbf{S}$ & $\mathbf{T i}$ & $\mathbf{T a}$ & $\mathbf{C o}$ & $\mathbf{F e}$ \\
\hline F22 & 0,17 & 0,04 & 2,11 & 0,93 & 0,35 & 0,30 & - & 0,14 & 0,04 & 0,01 & 0,01 & - & - & - & bal. \\
625 & 0,01 & 64,31 & 22,34 & 9,13 & 0,01 & 0,09 & 3,51 & 0,06 & $<0,01$ & 0,003 & 0,001 & 0,21 & 0,02 & 0,03 & 0,19 \\
\hline
\end{tabular}

Table 2. Welding procedure parameters

\begin{tabular}{lcccccc}
\hline $\begin{array}{l}\text { Preheat } \\
\text { temperature }\left({ }^{\circ} \mathbf{C}\right)\end{array}$ & $\begin{array}{c}\text { Current } \\
(\mathbf{A})\end{array}$ & $\begin{array}{c}\text { Voltage } \\
(\mathbf{V})\end{array}$ & $\begin{array}{c}\text { Wire feeding } \\
\text { speed }(\mathbf{m} / \mathbf{m i n})\end{array}$ & $\begin{array}{c}\text { Welding speed } \\
(\mathbf{m} / \mathbf{m i n})\end{array}$ & $\begin{array}{c}\text { Heat Input } \\
(\mathbf{k J} / \mathbf{m m})\end{array}$ & $\begin{array}{c}\text { BM thickness } \\
(\mathbf{m m})\end{array}$ \\
\hline $280 \leq \mathrm{T} \leq 340$ & 199,87 & 25,85 & 7 & 0,21 & 1,48 & 30 \\
\hline
\end{tabular}




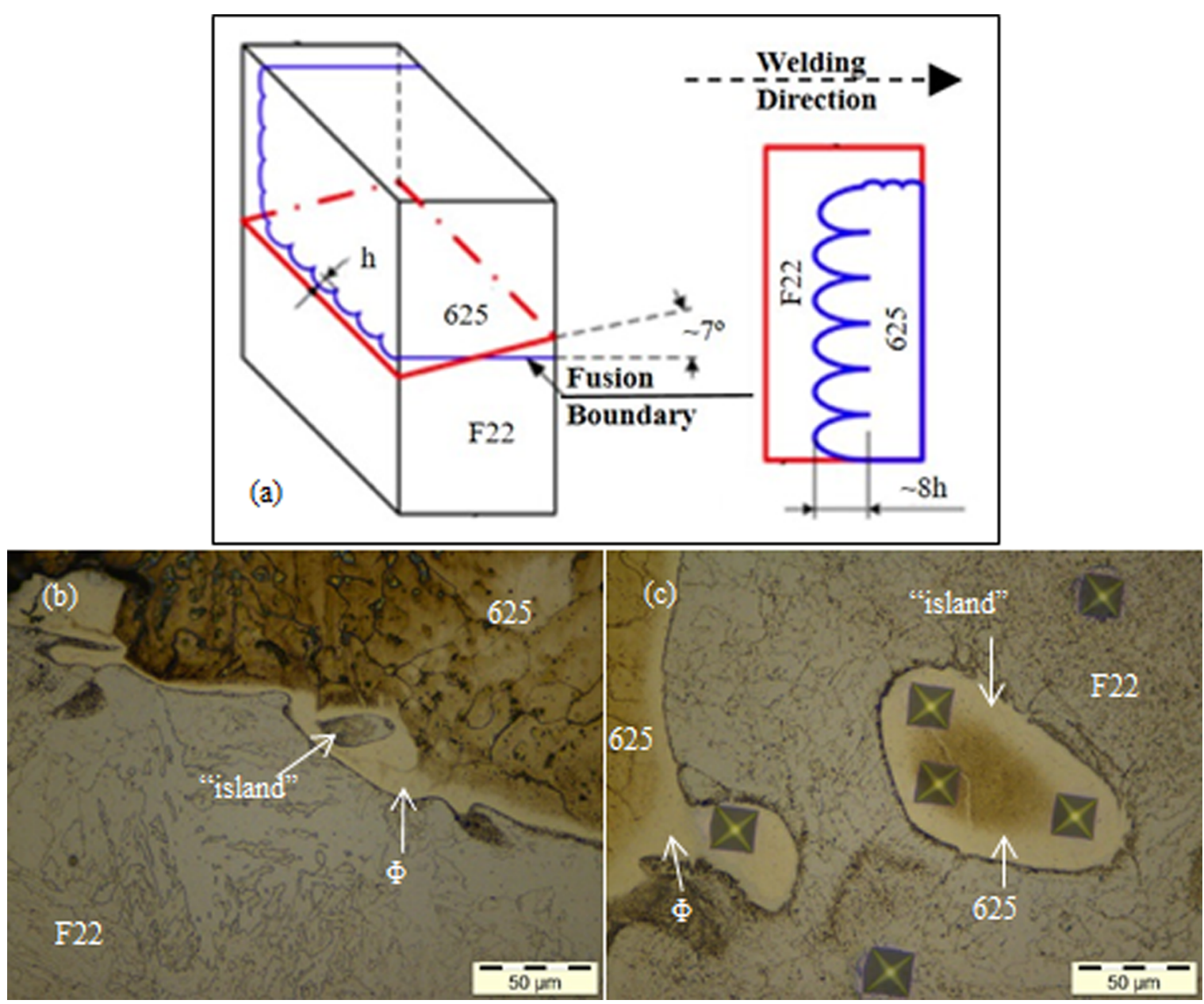

Figure 1. Samples (a) LAMS diagram ${ }^{27}$. (b) NCS image. (c) LAMS image.

The expansion of the transition region by the LAMS technique allows the analysis of microstructural characteristics more accurately, especially in terms of Vickers hardness, since it allows the adoption of loads up to $100 \mathrm{gf}$ in the planar growth zone $(\Phi)$, in the grain outline and in the "swirls" and "islands". While in normal cross-sectional samples, Figure 1(b), the indentations with the mentioned load transcend the PMZ, such as $\Phi$ zone and a 'island' region. Thus, the LAMS technique, Figure 1(c), is therefore very important in characterizing the microstructure and hardness of each zone individually. All samples were sanded with SiC-based abrasive material, with granulation of up to $\# 1200$ and 3 and $1 / 4 \mu \mathrm{m}$ diamond paste were used for polishing. Between sanding and polishing the samples were cleaned with acetone on ultrasound. The etchants, to reveal the microstructure of the F22 steel, were performed by immersion in $2 \%$ nital solution for $20 \mathrm{~s}$. This etch was followed by electrolytic etching with chromic acid at $10 \%$ at $5 \mathrm{~V}$ voltage and duration of 30 s with the aim of visualizing alloy 625 .

\subsection{Microstructural analysis}

All analyzes were performed around the fusion line (FL) of the buttering using samples in the as-welded and after PWHT conditions. In the microstructural analysis we used an Olympus BX41M - LED microscope with an image acquisition system, as well as a scanning electron microscope TESCAN model VEGA 3. By means of the dispersive energy detector (EDS) the chemical composition of the PMZs of the dissimilar interface was raised.

\subsection{Hardness and microhardness tests}

In the hardness and microhardness tests the samples as-welded and after PWHT were also considered. These were performed according to the recommendations of NACE Standard MR0175 ${ }^{16}$ and DNV Standard Offshore OS-F $101^{28}$. In the hardness tests, normal Rockwell C scale was used through a Mitutoyo model HR-320MS, while the microhardness tests were performed on Shimadzu model HMV-2, with load of $100 \mathrm{gf}\left(\mathrm{HV}_{0,1}\right)$ for 15s.

The microindentations were done in a punctual way (in the PMZs) and uniformly distributed along the weld metal (WM), HAZ and BM. In the first situation, LAMS samples (Figure 1 (c)) were used, due to the high area magnification that this technique allows. In the evenly distributed assays, NCS samples were used, which becomes efficient in the microstructural evaluation of the WM, HAZ and base metal (BM) regions. Figure 2, shows the demonstration scheme of 
the test procedure, represented by 9 columns of indentations grouped from 03 to 03 . In each group 62 impressions were made that totaled 186 indentations. The distance between the impressions of a group was $0.5 \mathrm{~mm}$, as shown in Figure 2. In addition, it should be noted that, from the five indentations highlighted in Figure 2, the mean value corresponding to one point of the curve of the hardness profile curve was taken. In total, three curves of the hardness profile were obtained, one being for a group of columns, resulting in the hardness profile curve presented in section 3.2.

\section{Resuslts and Discussion}

\subsection{Dissimilar interface microstructure in the as- welded and after PWHT conditions}

In the images of Figure 3, the microstructure of the buttering weld interface for NCS is shown. In the BM region the zone $\Delta$ (coarse grains) is characterized by the presence of a more evident decarburization and with larger grains of ferrite and / or retained austenite, Figure 3 (a). Comparing the images of Figure 3 , it is verified that this region is

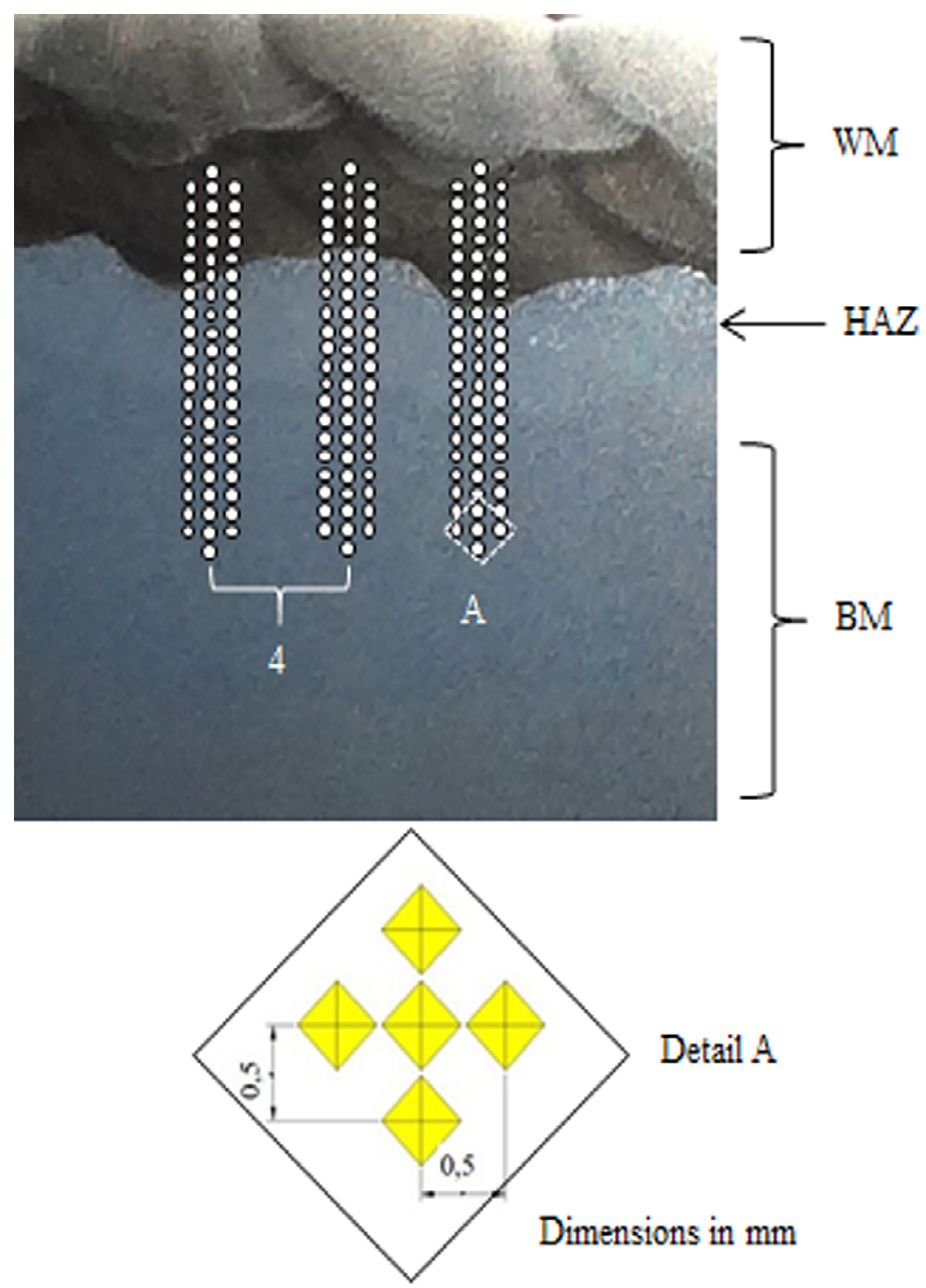

Figure 2. Distribution of indentations in the microhardness test. 
larger after the PWHT, indicating that the treatment favored decarburization of the zone $\Delta$. The width of this region varies along the NCS, having an average size of approximately 40 and $80 \mu \mathrm{m}$, in both conditions as-welded and after PWHT.

Figure 3 (b) shows the predominance of ferrite and / or retained austenite microstructure in the $\mathrm{BM}$, corroborating the effect of carbon diffusivity in the vicinity of the fusion line. Dodge et al..$^{22}$ observed that high values of carbon activity are present in ASTM A182 F22 steel when compared to the addition metal, with the carbon likely to diffuse in the direction of its thermodynamic activity gradient. Alexandrov et al. ${ }^{19}$ observed that after PWHT carbon tends to migrate from BM to austenitic WM. However, at typical PWHT temperatures the carbon activity in the weld metal remains comparatively low. This is attributed to the diffusivity in the austenite being considerably smaller than in the ferrite and the solubility of the carbon is higher ${ }^{22}$.

In the as-welded condition (Figure 3 (a)), the carbides were more elongated, suggestive of martensitic formation. While after PWHT (Figure 3 (b)), the microstructure presented a tempered morphology. This situation has been associated, in addition to the tempered martensite reaction, to several carbides, of which we can highlight $\mathrm{M}_{6} \mathrm{C}^{2}, \mathrm{M}_{7} \mathrm{C}_{3}^{25}$ and $\mathrm{M}_{23} \mathrm{C}^{2}$. Figure 4 shows the carbide formation curves related to ASTM A182 F22 steel in quenched and tempered condition ${ }^{29}$. Considering the PWHT of 6 hours at $677^{\circ} \mathrm{C}$, represented in Figure 4 by the yellow point, there is a favoring in the formation of $\mathrm{Fe}_{3} \mathrm{C}, \mathrm{Cr}_{7} \mathrm{C}_{3}$ and $\mathrm{Mo}_{2} \mathrm{C}$. Among these carbides mentioned, $\mathrm{Fe}_{3} \mathrm{C}$ and $\mathrm{Cr}_{7} \mathrm{C}_{3}$ commonly found in the interface of dissimilar welded joints, are particularly sensitive to hydrogen embrittlement. These carbides may act as hydrogen trapping sites and may be present at the dissimilar interface of the ARBL-Inconel $625^{23}$, providing a low energy fracture path mainly along the zone $\mathrm{M}^{22,30,31}$.

Following the WM in Figure 3 (a), the zone $\Phi$ is delimited by dashed lines between the $\Pi$ and $\Delta$ zones, or by the discontinuous formations, such as the "beach" type (red arrow). The zone $\Phi$ was continuous, with no contour inside and with microstructural shade suggestive of the
Body-centred cubic(BCC) matrix of alloy $625^{23,21,19}$. The formation of this zone is due to the low solidification rate and the high temperature gradient between the liquid weld metal and the solid base metal ${ }^{27}$. The thickness of this zone varied and, in general, had a dimension of approximately $10 \mu \mathrm{m}$. Dodge et al. ${ }^{22}$ found a planar zone with a thickness of $32 \mu \mathrm{m}$, applying a lower welding energy. A positive factor in reducing the thickness of zone $\Phi$ is the inhibition of formation of $\mathrm{Cr}_{7} \mathrm{C}_{3}$-type carbides in this zone, which may arise mainly after prolonged $\mathrm{PWHT}^{22}$. Considering that the time of PWHT employed was 6 hours, as well as the fact that the authors Dodge et al. ${ }^{22}$ treated the F22-alloy 625 joint for 10 hours and did not observe the formation of this carbide, the microhardness results presented suggesting an inhibition of this carbide in zone $\Phi$. Both the reduction of thickness and the inhibition of carbides are positive for applications in environments susceptible to hydrogen embrittlement.

Also related to Figure 3 (a), we highlight the cell and columnar dendritic zones (blue arrow) that make up the microstructure of the weld metal. Figure 3 (a) shows the cellular dendritic zone $(\Pi)$, located above the zone $\Phi$. The cell dendritic zone is formed due to a change in the solidification rate and temperature gradient $t^{27}$. The columnar dendritic region is characterized by the absence of dilution of the base metal as well as by the strongly oriented granulation according to the welding direction. The presence of precipitates of $\mathrm{Nb}$, $\mathrm{Mo}$ and $\mathrm{Cr}$ in the interdendritic and grain boundaries of alloy 625 is mentioned in the literature ${ }^{22,32}$.

The dilution at the dissimilar interface of buttered welds as-welded and after PWHT was raised via EDS to define the partially mixed zones (PMZs).

In Figure 5, in the section from 13 to $43 \mu \mathrm{m}$, it was verified that the increase of $\mathrm{Fe}$ presented a milder gradient, being accompanied by reductions of $\mathrm{Ni}$, whereas $\mathrm{Cr}$ and $\mathrm{Mo}$ showed practically no alterations. When the amplified SE image is observed and shown below the graph, it is verified that the behavior of $\mathrm{Fe}$ in this section comprises the entire zone $\Phi$ and part of zone $\Delta$. In relation to the zone $\Phi$, this presence of Fe was already expected, considering that it is frequently
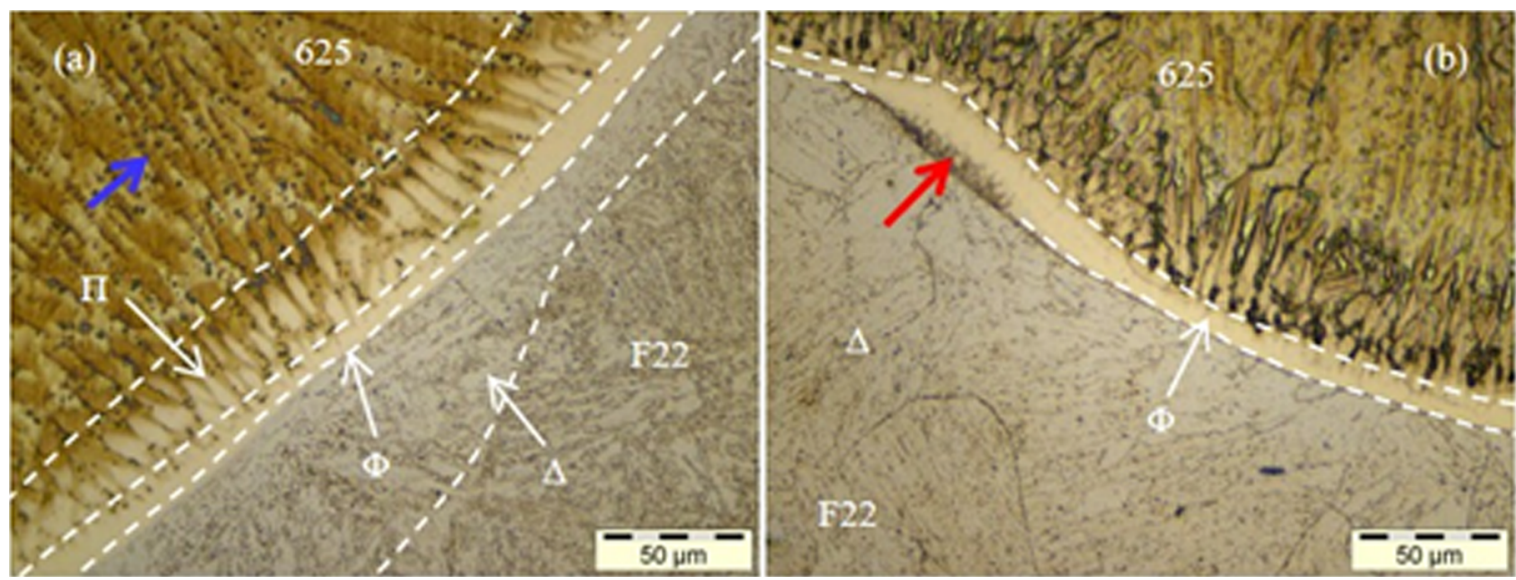

Figure 3. Microstructure, NCS, of the butter-weld interface. (a) as-welded (500x). (b) after PWHT (500x). 


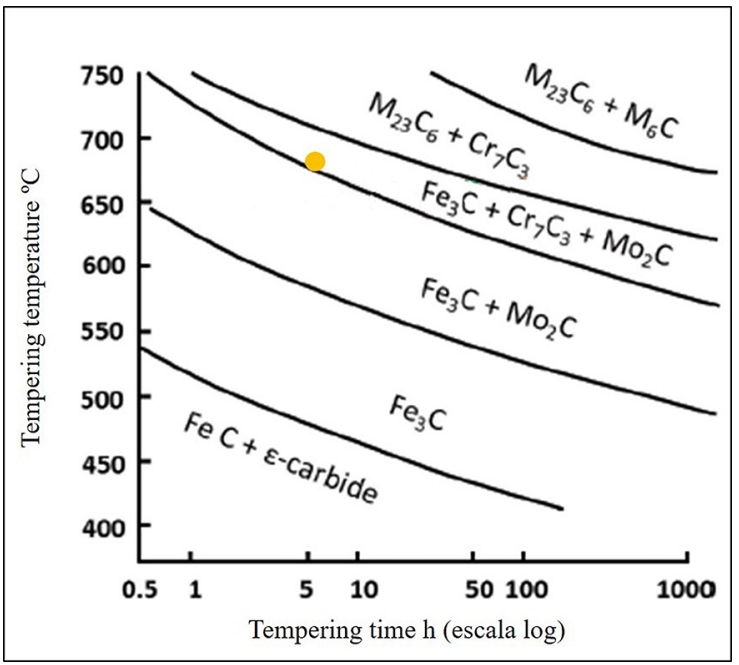

Figure 4. Formation of carbides in ASTM A182 F22 steel, with respect to temperature and time applied in the $\mathrm{PWHT}^{29}$

quoted in the literature in works employing the GMAW welding process for low alloy steel-Alloy 625 . Dodge et al. ${ }^{22}$ associate the presence of $\mathrm{Fe}$ in the zone $\Phi$ with the fact that the greatest composition changes occur in regions of planar solidification compared to the cellular dendritic areas (П).
With respect to the 43 to $49 \mu \mathrm{m}$ stretch of Figure 5, a steep increase of $\mathrm{Fe}$ is observed, whereas $\mathrm{Ni}$ and $\mathrm{Cr}$ behave in opposite ways. Mo, on the other hand, presents a very discrete reduction. Correlating the graph with the SE image of the magnification of the mapping line, two important pieces of information are verified: the first is the fact that the cited stretch is also associated with the zone $\Delta$ of the HAZ of the base metal, in this way it is observed that the dilution between BM and WM occurs before the melting line. Soysal et al.$^{33}$ associates the composition gradient at the dissimilar interface with the partial mixture between the liquid base metal and the melt pool, which, among other mechanisms, may be associated with the convection phenomenon in this mixture. The second information is that the welding process promoted a high content of $\mathrm{Cr}$ and $\mathrm{Ni}$ in the zone $\Delta$, supporting the previous discussion regarding the presence of $\mathrm{Cr}_{7} \mathrm{C}_{3}$ carbide in ASTM A182 F22 steel. The increase in $\mathrm{Ni}$ content favors the stabilization of austenite in the zone $\Delta$, as well as reducing the temperatures $\mathrm{A}_{1}$ and $\mathrm{A}_{3}$ in the "swirls" 19 .

Finally, the stretches from 0 to $13 \mu \mathrm{m}$ and from 49 to $80 \mu \mathrm{m}$ correspond respectively to the regions of WM and BM whose compositions did not suffer significant partial mixtures, prevailing the original composition.

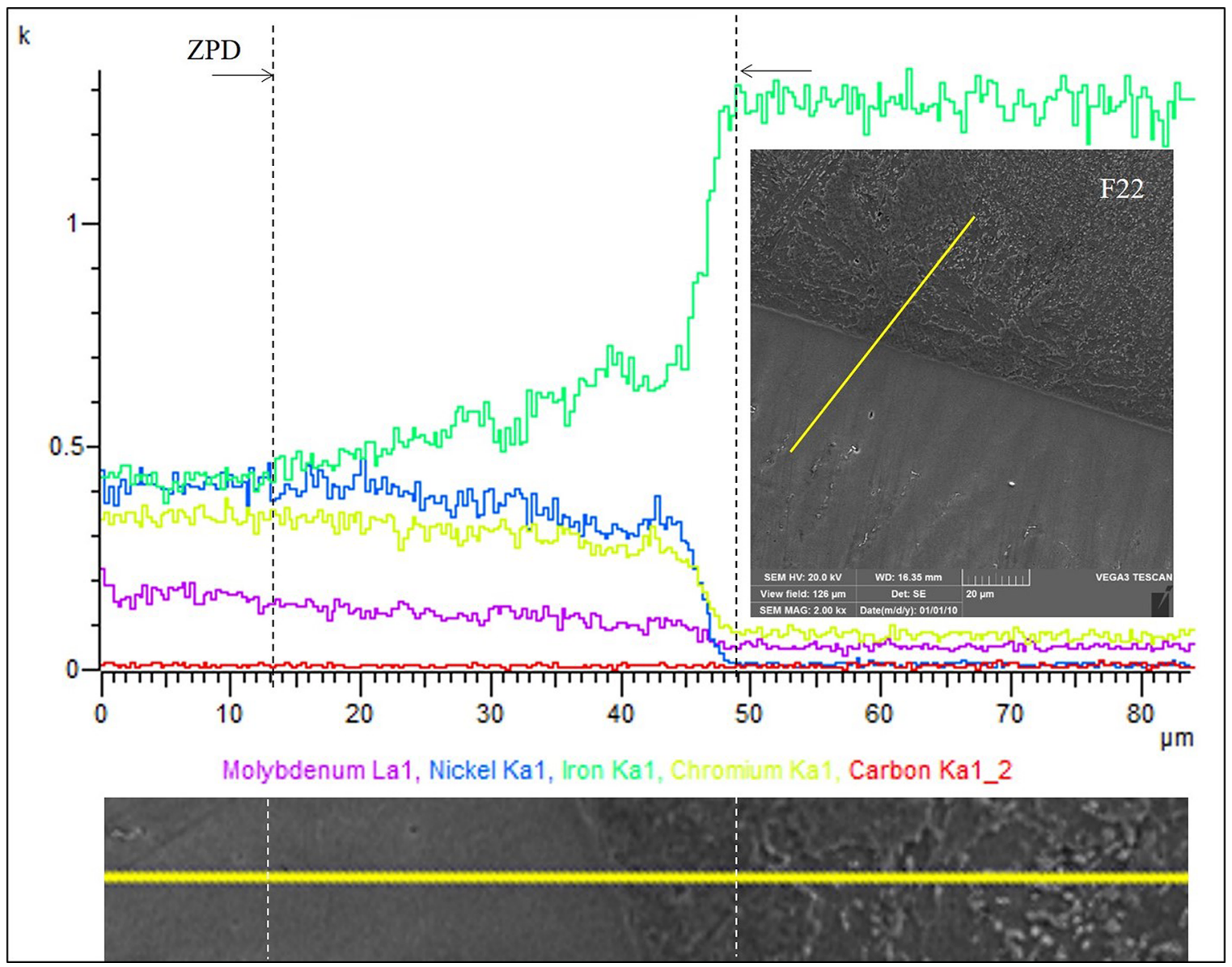

Figure 5. EDS, from the NCS, the butter weld interface as-welded. 
With respect to the EDS result of the butter welding in the condition after PWHT, Figure 6 , for the 15 to $28 \mu \mathrm{m}$ stretch, gradients of compositions similar to that of the material as welded were verified, proving the occurrence of dilution in the $\Delta$ and $\Phi$ zones. In the 7 to $15 \mu \mathrm{m}$ stretch, a soft composition gradient is observed in the cellular dendritic zone (П). As mentioned previously, some authors such as Beaugrand, Smith and Gittos $^{23}$ mention that zones $\Phi$ and $\Pi$ constitute PMZs. Also with respect to Figure 6, similar to the material as-welded, the presence of a higher $\mathrm{Cr}$ and $\mathrm{Ni}$ content in the zone $\Delta$ was also verified after PWHT. Considering that during this treatment the diffusion of carbon is favored, this result reinforces the presence of $\mathrm{Cr}_{7} \mathrm{C}_{3}$ carbide in ASTM A182 F22 steel.

The following are the optical microscopy images of the buttering weld of LAMS samples as-welded or after PWHT. Initially, it is important to note that the martensitic microstructure was not observed in buttering weld aswelded. In Figure 7 (a) formations of the type "swirls" and "islands", were presented with a microstructure similar to the one of the ferritic matrix. However, the microhardness values of these formations were close to $300 \mathrm{HV}_{0.1}$, according to examples shown in Figure 7 (a).
Thus, for joint F22-alloy 625 in as-welded condition, the results suggest the presence of retained austenite (RA) in the "swirls" and "islands". Note the point at $43 \mu \mathrm{m}$ in the EDS of the buttering welded as-welded, Figure 5 shows that the partially mixed zone has a nickel content close to that of the weld metal without dilution ( 0 to $13 \mu \mathrm{m})$. Probably, the higher nickel content generated a dilution in the region of these formations which, together with the cooling rate, favored the stabilization of the retained austenite at room temperature.

Figure 7 (b) shows the existence of macrosegregation, evidenced by dark regions in the base metal, known as zones M. These zones are characterized by the microstructural similarity with the base metal, having a very significant presence of martensite. Among the forms of presentation of the zone M, Figures 3 (b) and 7 (b), a predominance of the types "beaches" and "swirls", were quite defined. The authors Dodge et al. ${ }^{22}$ and Fenske et. al. ${ }^{21}$ mention that this type of formation is independent of the PWHT, being due to the welding parameters. Alexandrov et al. ${ }^{19}$, when studying weld 8630/625, found that the dilution between WM and BM may favor during the PWHT the partial or complete reversal of austenite in the "swirls".

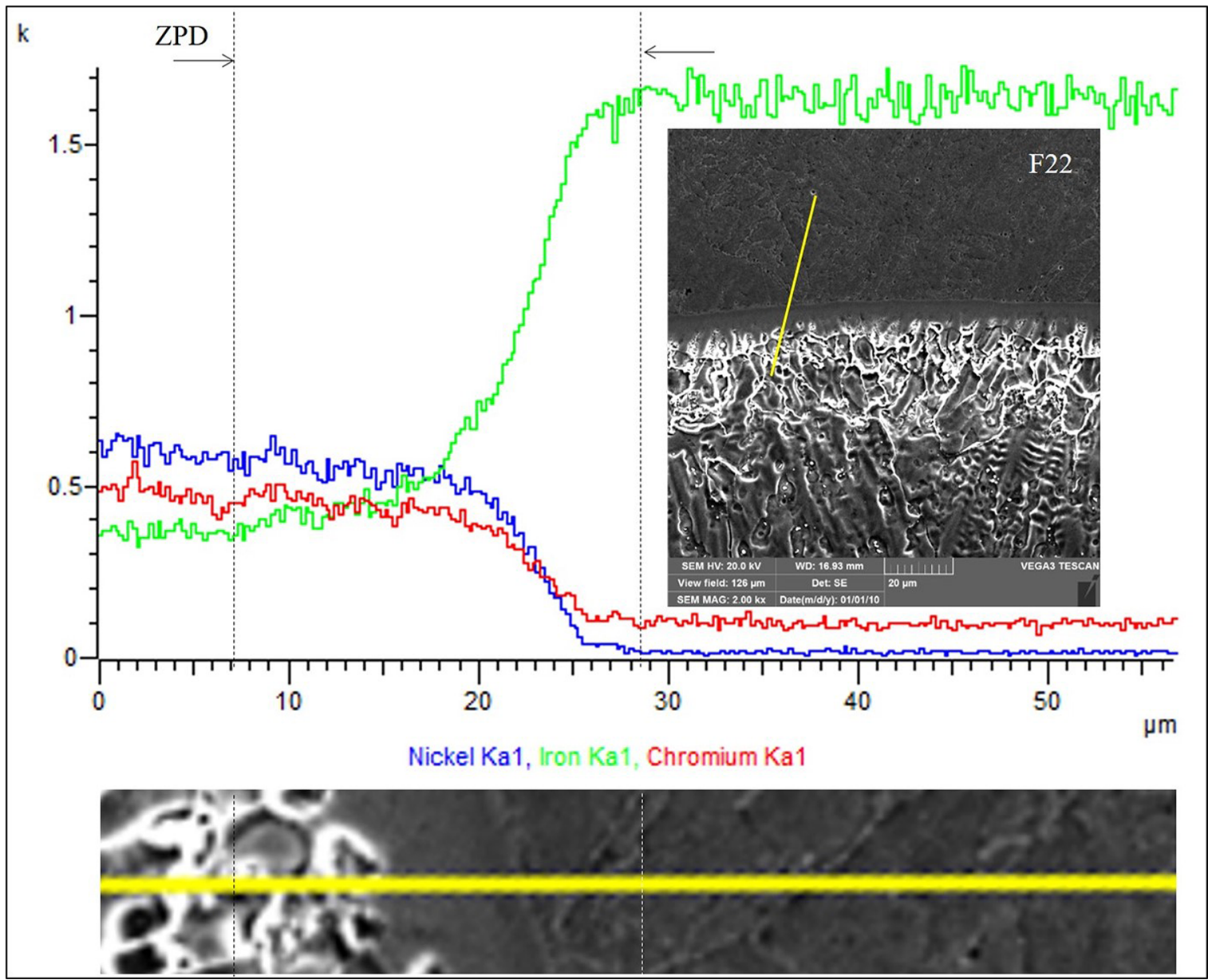

Figure 6. EDS, from the NCS, the butter weld interface after PWHT. 

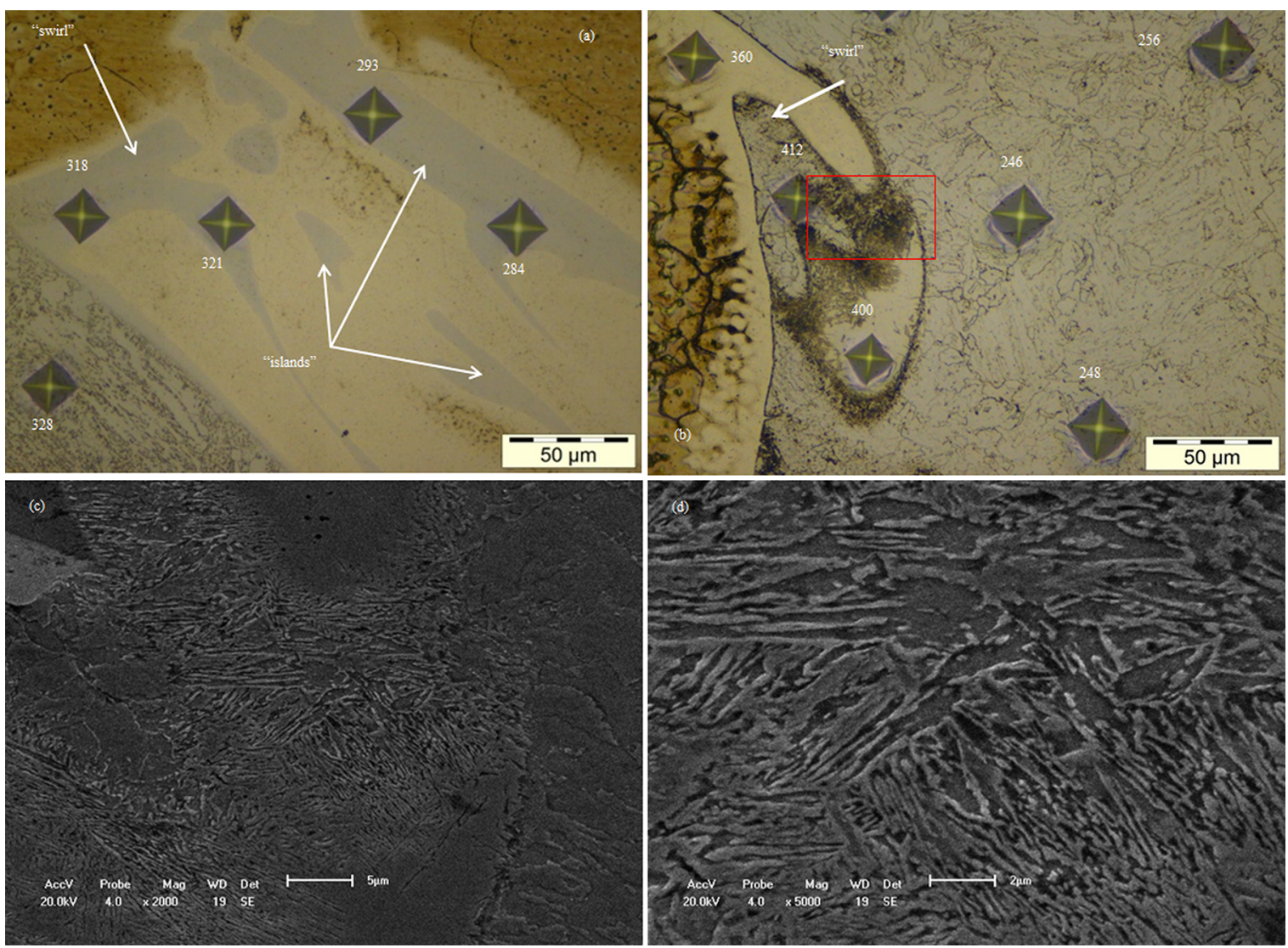

Figure 7. Buttering weld LAMS. (a) As-welded (500x). (b) MO from "swirl" (500x). (c) e (d) MEV of the region comprised by the red rectangle, respectively, (2000x) e (5000x).

In the MEV images of Figure 7 (c) and (d), which correspond to the red rectangle region of Figure 7 (b), elongated microstructures are observed, suggesting martensitic formation. The Vickers microhardness values, in the vicinity of this microstructure (Figure 7 (b)), were approximately $400 \mathrm{HV}_{0.1}$, which are compatible with this type of formation. Authors Dai \& Lippold ${ }^{17}$ observed the presence of martensite in the PMZs of samples of steel treated 8630 above $600^{\circ} \mathrm{C}$, this formation being justified by the occurrence of austenitic transformation during the PWHT. They found that, even at very low cooling rates, this martensite formed and exhibited hardness levels around 330 to $450 \mathrm{VHN}$.

As for the martensitic formation, verified after the PWHT of 6 hours at $677^{\circ} \mathrm{C}$, it may have been due to a saturation of carbon in the retained austenite (RA), promoting martensitic formation with air cooling. Likewise, authors, Fenske et al. ${ }^{21}$ mention that the high content of $\mathrm{Ni}$ can reduce the temperature $\mathrm{A}_{\mathrm{Cl}}$, making it lower than the temperature of PWHT, favoring the reactivation in the discontinuous PMZs with microstructure of the base metal, consequently generating martensite after cooling.

Finally, the results of EDS presented indicate that the PMZs is composed of the zones $\Delta, \Phi, \Pi$ and $\mathrm{M}$. With the exception of zone $\Delta$, the other three zones mentioned are in accordance with the definition adopted by Beaugrand, Smith \& Gittos $^{23}$. It is important to note that compositional changes within these zones have been considered independent of the duration of PWHT, indicating that it occurs during the welding process ${ }^{21}$.

Another observed formation in the welded joint studied was the "islands" shown in Figure 8, which, unlike those specified in Figure 7, showed WM microstructure being surrounded by BM. The observed formation suggests the presence of mechanism in which the liquid temperature of the melt pool is greater than the liquid temperature of the base metal. The presence of this mechanism together with the convection of the fusion pool may favor the presence of this formation.

In the image of Figure 8 (b), we can see formations that have been called "fingers", and correspond to the WM penetration in BM. Several authors, among others, Alexandrov et al. ${ }^{19}$ characterized the microstructure of this formation as austenitic, similar to the planar zone. Although the formations are present in the material after PWHT, Fenske et al. ${ }^{21}$ attribute the presence of these formations to the welding process and not to the PWHT. These authors observed, during the solidification, very steep temperature gradients in the planar growth zone $(\Phi)$. Thus, during solidification, 

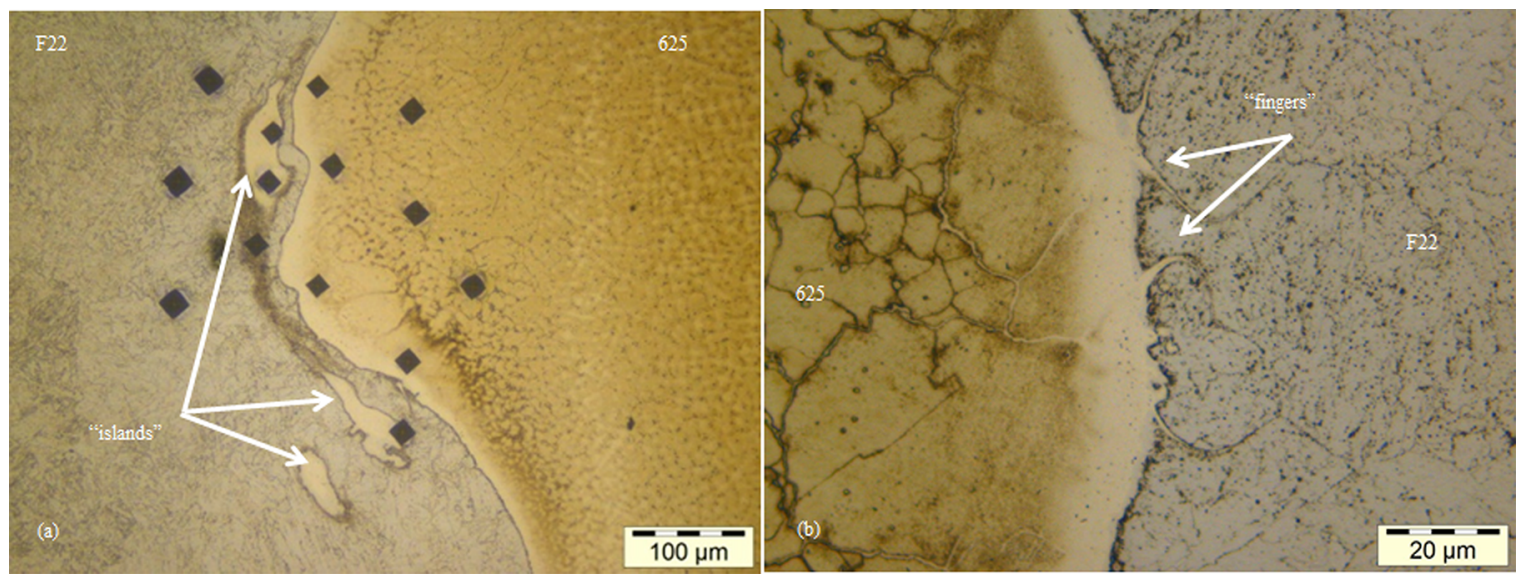

Figure 8. LAMS optical microscopy of buttering weld after PWHT. (a) "Islands " (200x). (b) "fingers" (1000x).

the liquid which may have a temperature lower than the solid phase, together with the convection of the melt pool, can promote penetration and solidification of the "fingers".

\subsection{Hardness and microhardness in the as-welded and after PWHT conditions}

The hardness and microhardness tests were performed on the buttering welds as-welded and after PWHT. Regarding the weld beads, the hardness tests were performed in the transverse (ST) and longitudinal (SL) sections. In Figure 9, the average values of Rockwell $\mathrm{C}$ hardness with their respective standard deviations can be verified for ST and SL. For the analyzed sections indentations were performed in four regions, base metal (BM), HAZ and weld metal (WM - 1st and 2nd beads), in accordance with NACE MR0175 ${ }^{16}$.

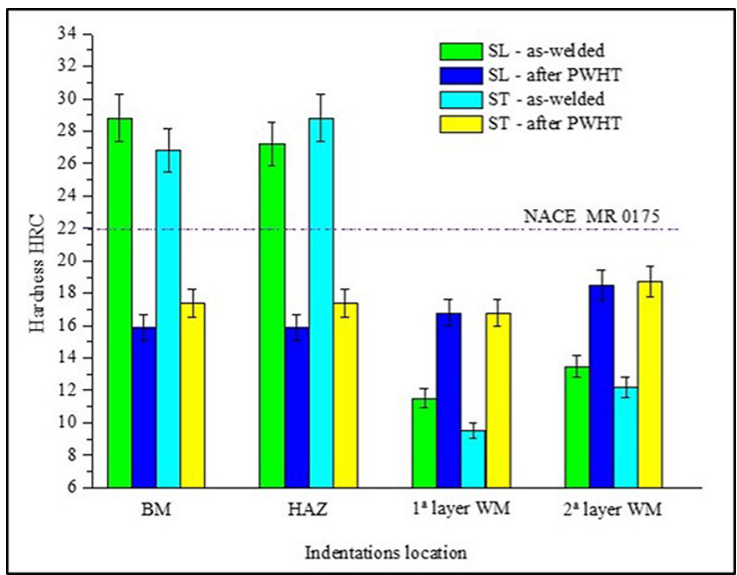

Figure 9. Mean Rockwell C hardness with standard deviation for the BM, HAZ and WM regions (1st and 2nd beads) for the buttering weld.

Analyzing the results presented in Figure 9, it was observed that in the as-welded condition, the BM and HAZ of the buttering weld, in both sections SL (green) and ST (light blue) presented average values between 26 and 28 HRC. These results were already expected due to the use of ASTM A182 F22 in the forged state, as well as the fact that the welding thermal input and the subsequent cooling favor the formation of microstructures with high levels of residual tension and hardness in the HAZ. In relation to the 1st and 2nd weld beads, sections SL (green) and ST (light blue), there was a hardness increase of the 2 nd layer of filler metal in relation to the 1st layer, for both sections. This behavior may be related to the precipitation hardening coming from the thermal supply of the multiple beads of the buttering weld.

From the dark blue (SL - after PWHT) and yellow (ST - after PWHT) columns of Figure 9, it is observed that the mean values of hardness together with the standard deviation values are close to $18 \mathrm{HRC}$ for the $\mathrm{BM}$ and $\mathrm{HAZ}$ regions. This result shows that the HJP of 19,742 allowed the reduction, which was expected, of the HAZ hardness level. The materials applied in environments containing $\mathrm{H}_{2} \mathrm{~S}$ in the production of oil and gas must meet, among other criteria, the hardness levels established by NACE MR0175 $5^{16}$, in order to reduce hydrogen embrittlement. This standard states that after the PWHT the maximum hardness of the BM and HAZ should not exceed 22HRC. In the case of weld beads, dark blue (SL - after PWHT) and yellow (ST - after PWHT) columns of Figure 9, a hardness increase is observed for both the 1st and 2nd weld beads, suggesting that the PWHT also promoted precipitation hardening in the multipass cords of the buttering weld.

Figure 10 shows the microhardness profiles, with $95 \%$ reliability, for the samples extracted along the NCS of the buttering weld as-welded and after PWHT. These profiles were obtained from the arithmetic mean of the three profiles that were raised according to the detail of Figure 3.

In the as-welded condition, red curve, the microhardness results of the weld metal were lower than the HAZ and the base metal. In the three analyzed regions a behavior of non-uniform hardness was verified, being this fact more accentuated in the region of the HAZ. Dai \& Lippold ${ }^{25}$ found similar behavior in this region, which was associated with the tempering effect of the multibead overlapping process. 


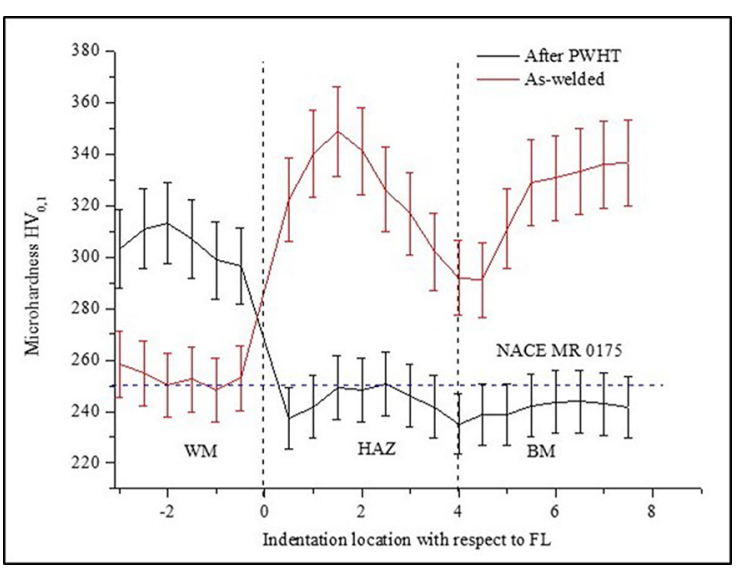

Figure 10. Mean Vickers microhardness profiles (NCS) of the WM, HAZ and BM regions.

In the stretch between 1 and $2 \mathrm{~mm}$, Figure 10 shows peaks of hardness (minimum value of $340 \mathrm{HV}_{0.1}$ ) that may be associated with the presence of a refinement of the HAZ structure in this region. Differently from the 0 to $1 \mathrm{~mm}$ and 2 to $4,5 \mathrm{~mm}$ stretches corresponding respectively to the regions near the fusion line (FL) (Figure 6.3) and transition (HAZ - BM) that presented ferrite with coarse granulation. Fenske ${ }^{34}$ cites the presence of a microstructure, in the HAZ, composed of regions of coarse grains, refined and recrystallized.

Similar to the as-welded condition, the microhardness results of the buttering weld after PWHT, black curve, were obtained. The obtained hardness profiles behaved in the opposite way, that is, while the hardness decreased in the HAZ and BM, an increase in the weld metal was observed. The heterogeneity mainly in HAZ was maintained after PWHT, however a significant reduction was observed in the peaks of hardness previously mentioned, whose maximum value was $255 \mathrm{HV}_{0,1}$. When the margin of error of $5 \%$ is considered, it is observed that the hardness results of the HAZ were close to the value of $250 \mathrm{HV}$ specified by NACE MR $0175^{16}$.

From the results presented in Figure 10, the mean values and standard deviations for the WM, HAZ and BM regions were raised, the results of which are shown in Figure 11. With respect to the WM of this Figure, a 17\% increase in the average value of hardness was observed, suggesting that PWHT promoted precipitation hardening. For the HAZ region (Figure 11), it can be observed that, in terms of mean values, the PWHT allowed a reduction of the hardness by $25 \%$ where, despite the peaks of hardness verified in Figure 10 , the mean values were below $250 \mathrm{HV}$, therefore, within the scope of the recommendations of the NACE MR $0175^{16}$ standard. Finally, the mean values for the BM region (Figure 11) behaved in a manner similar to those of the HAZ.

In the graph of Figure 12 the mean values of punctual microhardness along with the standard deviation for the areas $\Delta, \Phi, \Pi, \mathrm{RA}$ and $\mathrm{M}$ are shown in the as-welded and after PWHT conditions. Complementing the punctual microhardness values shown in Figure 7(a) for retained

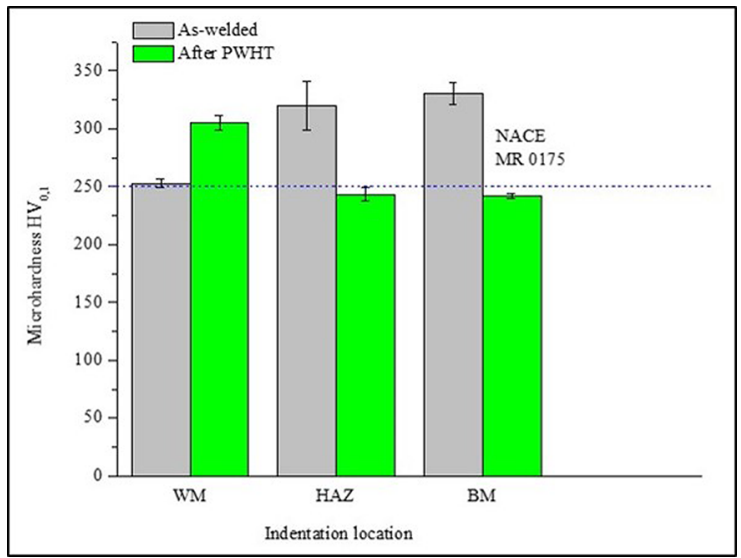

Figure 11. Mean and standard deviation of Vickers microhardness (LAMS), regions of (WM), HAZ and (BM), as-welded and after PWHT.

austenite (RA), more examples can be seen in Figure 13 for $\Delta, \Phi$ and $M$ zones.

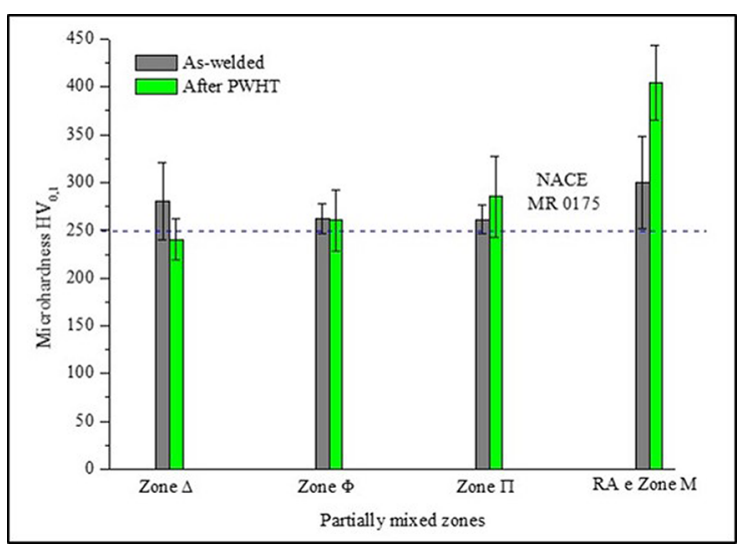

Figure 12. Mean microhardness values and standard deviation for PMZs.

With respect to zone $\Delta$ the data of the graph of Figure 12 demonstrate that after PWHT this zone presented a mean hardness of $240 \mathrm{HV}_{0,1}$ according to NACE MR0175 $5^{16}$ standard. However, it is worth noting that, when considering the standard deviation, values higher than $250 \mathrm{HV}_{0,1}$ of the aforementioned norm are considered. Thus, in contrast to the results of HRC hardness and uniformly distributed microhardness, which showed that HAZ met the standard even considering the standard deviation, the punctual microhardness confirms the presence of harder regions in this zone after PWHT.

Considering the hardness results of zone $\Phi$, Figure 12, it is verified that the hardness level of this zone remained practically unchanged after PWHT. This behavior is very promising for the application of the joint in environments facilitating hydrogen embrittlement, since they demonstrate the non-favoring of carbides in zone $\Phi$, which have been closely related to the failures of these joints. It is important to note that this area had an average hardness of $260 \mathrm{HV}_{0.1}$, 

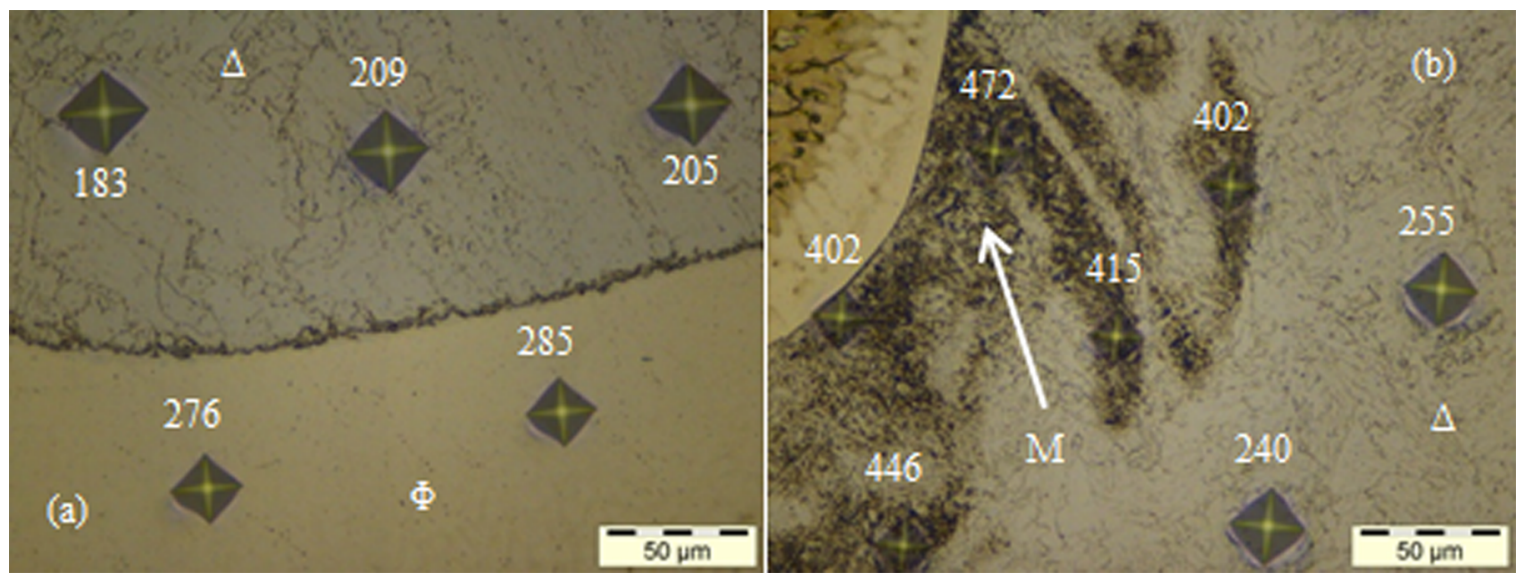

Figure 13. MO with microindentations in the PMZs. (a) zones $\Phi$ and $\Delta$. (b) zones $\Delta, M, \Phi$ and $\Pi$.

according to Dai \& Lippold ${ }^{25}$ who observed values above $250 \mathrm{HV}_{0.1}$ for this zone. They mention that this zone admits higher hardness values after the PWHT, since it is narrow when compared to the region of coarse grains of the HAZ, which causes the diffusivity of the hydrogen in the $\Phi$ austenitic zone to be smaller than in the region of coarse grains of the HAZ ${ }^{35}$. Furthermore, Dodge et al..$^{22}$ cite that the precipitation of carbides in the weld metal can affect the mechanical performance of the dissimilar joints.

For the zone $\Pi$ the results of Figure 12 show an expected increase of the microhardness after PWHT, fact that was also verified in the other tests of hardness raised in the weld metal. Possibly this fact is associated with precipitation hardening ${ }^{27,25}$.

In the last two columns presented on the right side of the graph of Figure 12, the results for RA and martensite, respectively, as-welded and after PWHT are obtained. As can be seen, the mean hardness level of $300 \pm 48.3 \mathrm{HV}_{0.1}$ is consistent for the retained austenite, as well as $400 \pm 38.6$ $\mathrm{HV}_{0.1}$, consistent with martensite. These results suggest that the PWHT favored the formation of martensite and, corroborate with the microstructure presented in the images of Figure 13(b).

\section{Conclusions}

In this work, the influence of the welding process and PWHT on the dissimilar interface of ASTM A182 F22 steel with alloy 625 was investigated. Thus, based on the research developed, the following conclusions were reached:

The welding process favored the dilution of $\mathrm{Ni}$ in the zone $\Delta$, contributing to the presence of retained austenite (RA) at the dissimilar interface. In turn, after PWHT, zone $M$ presented with characteristics of fresh martensite.

The low-angle microsectioning (LAMS) technique allowed the use of the load level $\left(\mathrm{HV}_{0,1}\right)$ in the PMZs.

It was observed that the PMZs consisted of $\Delta, \Phi, \Pi$ and M zones. It was also observed formations such as "swirls," "beaches", "fingers" and "islands".

The buttering of ASTM A182 F22 steel - alloy 625 met the hardness criteria recommended by NACE MR0175 for HAZ.
With the LAMS technique it was possible to verify that the zone $\mathrm{M}$ presented with hardness above $400 \mathrm{HV}_{0,1}$, proving the carbon diffusion in the base metal.

From these results it can be concluded that the LAMS technique is very important in the hardness survey around the melting line.

\section{Acknowledgements}

We are grateful for the support of the Graduate Programs in Materials Science and Engineering and Mechanical Engineering at the Federal University of Paraíba (UFPB). We also thank Bruna Marcela and the Federal Institute of Education, Science and Technology of Rio Grande do Norte (IFRN) for the technical support in conducting SEM analyzes. Finally, the authors thank Peraltech Machining Solutions and Sandvik do Brasil for the technical support and donation of the machining supplies.

\section{References}

1. Ramkumar KD, Abraham WS, Viyash V, Arivazhagan N, Rabel AM. Investigations on the microstructure, tensile strength and high temperature corrosion behaviour of Inconel 625 and Inconel 718 dissimilar joints. Journal of Manufacturing Processes. 2017;25:306-22.

2. Dodge MF. The effect of heat treatment on the embrittlement of dissimilar welded joints [thesis]. Leicester, UK: University of Leicester - Department of Engineering; 2014.

3. Monine VI, Gonzaga RS, Farias FWC, Passos EKD, Payão Filho JC. Study of mechanical behavior and X-ray elastic constants of nickel alloy weld overlay. Materials Research. 2019;22(4):1-10.

4. Lu X, Wang D, Wan D, Zhang ZB, Kheradmand N, Barnoush A. Effect of electrochemical charging on the hydrogen embrittlement susceptibility of alloy 718. Acta Materialia. 2019;179:36-48.

5. Bansod AV, Patil AP, Verma J, Shukla S. Microstructure, mechanical and electrochemical evaluation of dissimilar low Ni SS and 304 SS using different filler materials. Materials Research. 2019;22(4):e20170203. 
6. Fassina P, Brunella MF, Lazzari L, Re G, Vergani L, Sciuccati A. Effect of hydrogen and low temperature on fatigue crack growth of pipeline steels. Engineering Fracture Mechanics. $2013 ; 103: 10-25$

7. Carvalho JP, Vilar EO, Araújo BA. A critical review and experimental analysis of the equation recommended by ASTM G148-97 and ISO 17081: 2004 for the calculation of the hydrogen diffusivity in metals and alloys. International Journal of Hydrogen Energy. 2017;42(1):681-8.

8. Rajabipour A, Melchers RE. Capacity of pitting corroded pipes under hydrogen assisted cracking. International Journal of Hydrogen Energy. 2015;40(30):9388-99.

9. Vellaichamy L, Gerard PBT, Paulraj S. Mechanical and metallurgical characterization of laser welding on P91 ferritic steel and incoloy $800 \mathrm{HT}$ dissimilar joints. Materials Research. 2018;21(2):e20170911.

10. Burk JD, Ribardo CL. Thunder horse-materials, welding and corrosion challenges and solutions. In: Offshore Technology Conference; 2010 may 3-6; Houston, Texas, USA. Houston, Texas: OTC; 2010. p. 1-11.

11. Jemblie L, Olden V, Akselsen OM. A coupled diffusion and cohesive zone modelling approach for numerically assessing hydrogen embrittlement of steel structures. International Journal of Hydrogen Energy. 2017;42(16):11980-95.

12. Xia C, Zhao M, Sun W, Li H, Liu P. Microstructure and properties of 3D printed Inconel 718 joint brazed with $\mathrm{BNi}-2$ amorphous filler metal. Materials Research. 2019;22(1):e20180348.

13. Haldorsen LM, Rorvik G, Dodge M, Sotoudeh K. Recent experiences with cracking of load bearing dissimilar metal welds on subsea production systems. In: Proceedings of the ASME 2017 - 36th International Conference on Ocean, Offshore and Arctic Engineering; 2017 jun 25-30; Trondheim, Norway. Trondheim, Norway: OMAE; 2017. p. 1-13.

14. Zhou C, Huang Q, Guo Q, Zheng J, Chen X, Zhu J, et al. Sulphide stress cracking behaviour of the dissimilar metal welded joint of X60 pipeline steel and Inconel 625 alloy. Corrosion Science. 2016;110:242-52.

15. Rathod DW, Singh PK, Pandey S, Aravindan S. Effect of bufferlayered buttering on microstructure and mechanical properties of dissimilar metal weld joints for nuclear plant application. Materials Science and Engineering: A. 2016;666:100-13.

16. International Organization for Standardization (ISO). ISO 15156-1. Petroleum and natural gas industries - Materials for use in H2S-containing environments in oil and gas production. Houston, Texas, USA: NACE International; 2015.

17. Dai T, Lippold JC. Tempering effect on the fusion boundary region of alloy 625 weld overlay on 8630 steel. Welding in the World. 2018;62:535-50.

18. Poorhaydari K, Patchett BM, Ivey DG. Estimation of cooling rate in the welding of plates with intermediate thickness. Welding Journal. 2005;(Suppl 1):149s-155s.

19. Alexandrov BT, Lippold JC, Sowards JW, Hope AT, Saltzmann DR. Fusion boundary microstructure evolution associated with embrittlement of Ni-base alloy overlays applied to carbon steel. Welding in the World. 2013;57(1):39-53.
20. Jemblie L, Bjaaland H, Nyhus B, Olden V, Akselsen OM. Fracture toughness and hydrogen embrittlement susceptibility on the interface of clad steel pipes with and without a Ni-interlayer. Materials Science Engineering: A. 2017;685:87-94.

21. Fenske JA, Robertson IM, Ayer R, Hukle M, Lillig MHD, Newbury B. Microstructure and hydrogen-induced failure mechanisms in $\mathrm{Fe}$ and $\mathrm{Ni}$ alloy weldments. Metall Mater Trans A. 2012;43:2012-3011.

22. Dodge MF, Dong HB, Gittos MF, Mobberley T. Fusion zone microstructure associated with embrittlement of subsea dissimilar joints. In: Proceedings of the ASME 2014 - 33rd International Conference on Ocean, Offshore and Arctic Engineering; 2014 jun 8-13; San Francisco, California, USA. San Francisco, California: OMAE; 2014. p. 1-11.

23. Beaugrand VCM, Smith LS, Gittos MF. Hydrogen embrittlement of $8630 \mathrm{M} / 625$ subsea dissimilar joints: factors that influence the performance. In: Proceedings of the 28th International Conference on Ocean, Offshore and Arctic Engineering; 2009 mar 22-26; Honolulu, Hawaii, USA. Honolulu, Hawaii: OMAE; 2009. p. 1-10.

24. Dai T, Lippold JC. The effect of postweld heat treatment on hydrogen-assisted cracking of 8630/alloy 625 overlay. Welding in the World. 2018;97:75s-90s

25. Dai T, Lippold JC. Tempering behavior of the fusion boundary region of an F22/625 weld overlay. Weld Journal. 2017;96:467s-80s.

26. Hollomon JH, Jaffe LD. Time-temperatures relations in tempering steel. Transactions of the American Institute of Mining and Metallurgical Engineering. 1945;162:223-49.

27. Bourgeois D. Hydrogen assisted crack in dissimilar metal welds for subsea service under cathodic protection [thesis]. Columbus, OH: Ohio State University; 2015.

28. Det Norske Veritas (DNV). Offshore Standard DNV-OS-F101 - Submarine Pipeline Systems. Hovik, Norway: DNV; 2008.

29. Baker RG, Nutting J. The tempering of 2.25Cr-1Mo steel after quenching and normalizing. The Journal of the Iron and Steel Institute. 1959;192:257-68

30. Fenske JA, Hukle MW, Newbury B, Gordon JR, Noecker R, Robertson IM. Hydrogen induced mechanical property behavior of dissimilar weld metal interfaces. In: Proceedings of the ASME $2011-30^{\text {th }}$ International Conference on Ocean, Offshore and Arctic Engineering; 2011 jun 19-24; Rotterdam, Netherlands. Rotterdam, Netherlands: OMAE; 2011. p. 1-8.

31. Olden V, Kvaale PE, Simensen PA, Aaldstedt S, Solberg JK. The effect of pwht on the material properties and micro structure in inconel 625 and inconel 725 buttered joints. In: Proceedings of OMAE 2003 - The $22^{\text {nd }}$ International Conference on Ocean, Offshore and Arctic Engineering; 2003 jun 8-13; Cancun, Mexico. Cancun, Mexico: OMAE; 2003. p. 1-7.

32. Pereira FGL, Lourenço JM, Nascimento RM, Castro NA. Fracture behavior and fatigue performance of inconel 625 . Materials Research. 2018;21(4):e20171089.

33. Soysal T, Kou S, Tat D, Pasang T. Macrosegregation in dissimilarmetal fusion welding. Acta Materialia. 2016;110:149-60. 
34. Fenske JA. Microstructure and hydrogen induced failure mechanisms in iron-nickel weldments [thesis]. Urbana-Champaign, IL: University of Illinois; 2010.
35. Cheng YF, Niu L. Mechanism for hydrogen evolution reaction on pipeline steel in near-neutral $\mathrm{pH}$ solution. Electrochemistry Communications. 2007;9(4):558-62. 